\title{
Review Article \\ Optical Remote Sensing of Oil Spills in the Ocean: What Is Really Possible?
}

\author{
Chuanmin Hu $\mathbb{D},{ }^{1}$ Yingcheng Lu, ${ }^{1,2}$ Shaojie Sun, ${ }^{3,4}$ and Yongxue Liu $\mathbb{D}^{2}$ \\ ${ }^{1}$ College of Marine Science, University of South Florida, 140 Seventh Avenue South, St. Petersburg, FL 33701, USA \\ ${ }^{2}$ International Institute for Earth System Science, Nanjing University, 210023, China \\ ${ }^{3}$ School of Marine Sciences, Sun Yat-sen University, Zhuhai 519082, China \\ ${ }^{4}$ Southern Marine Science and Engineering Guangdong Laboratory, Zhuhai 519080, China \\ Correspondence should be addressed to Chuanmin Hu; huc@usf.edu
}

Received 31 October 2020; Accepted 6 January 2021; Published 13 February 2021

Copyright ( 2021 Chuanmin Hu et al. Exclusive Licensee Aerospace Information Research Institute, Chinese Academy of Sciences. Distributed under a Creative Commons Attribution License (CC BY 4.0).

\begin{abstract}
Optical remote sensing (ORS) of reflected sun light has been used to assess oil spills in the ocean for several decades. While most applications are toward simple presence/absence detections based on the spatial contrast between oiled water and oil-free water, recent advances indicate the possibility of classifying oil types and quantifying oil volumes based on their spectral contrasts with oil-free water. However, a review of the current literature suggests that there is still confusion on whether this is possible and, if so, how. Here, based on the recent findings from numerical models, laboratory measurements, and applications to satellite or airborne imagery, we attempt to clarify this situation by summarizing (1) the optics behind oil spill remote sensing, and in turn, (2) how to interpret optical remote sensing imagery based on optical principles. In the end, we discuss the existing limitations and challenges as well as pathways forward to advance ORS of oil spills.
\end{abstract}

\section{Introduction}

Remote sensing through airborne or satellite platforms provides rapid and synoptic measurements of the targets, therefore has been used for decades to assess oil spills in the ocean, from near real-time mapping to postspill assessment (see reviews by [1-5]). As of 22 August 2020, a keyword search of "remote sensing" and "oil spill" in http://webofscience .com resulted in 679 papers. The remote sensing techniques range from synthetic aperture radar (SAR), Light Detection and Ranging (LiDAR), thermal infrared, and optical means (visible-near infrared-shortwave infrared). Of these techniques, SAR provides imagery under all-weather conditions, where the presence of oil on the ocean surface suppresses surface capillary waves and short gravity waves, leading to reduced Bragg scattering and therefore negative contrast from the surrounding water in SAR imagery. One limitation is that due to the single band (or wavelength) used in SAR measurements, most information is from the spatial contrast of the detected feature along with the feature's morphology or texture. Unless some a priori knowledge is available, this often makes it difficult to distinguish surface oil from other features that can also make similar spatial contrasts in SAR imagery (e.g., phytoplankton surfactant, freshwater slicks, current shears, floating algae, and among others), let alone classifying oil types or quantifying oil volume despite some preliminary attempts $[6,7]$.

Another popular technique is optical remote sensing (ORS) of reflected sun light in the visible-near infraredshortwave infrared (vis-NIR-SWIR) wavelengths, which is the subject of this paper. Although ORS imagery suffers from frequent clouds (i.e., about $2 / 3$ of the global ocean is covered by clouds at any moment, [8]), this limitation is compensated by the multiple ORS sensors currently in orbit and multiband spectral data from any individual sensor. Indeed, all ORS sensors, regardless of their spatial resolution, swath width, sensitivity (i.e., signal-to-noise ratio), or number of spectral bands, can be used for oil spill assessment. The use of ORS to assess oil spills can actually be traced back to the early 1980s, when Hooper et al. [9] used GOES, TRIOS, and ERTS (Landsat) satellite images to observe oil distributions after the Ixtoc oil spill off Mexico. More complete analysis of this spill has been provided by Sun et al. [10]. While it is difficult to provide a complete list, Table 1 shows the most often used 
TABLE 1: Some of the ORS sensors for oil spill assessments and their sensor characteristics. Listed are those currently still in orbit whose data are available to the public.

\begin{tabular}{lcccc}
\hline Sensor & Start & Res. $(\mathrm{m})$ & \# of VIS-SWIR bands & Revisit (days) \\
\hline MODIS & 2000 & $250-1000$ & $16(412-2130)$ & $1-2$ \\
VIIRS & 2012 & $375-750$ & $14(412-2130)$ & 1 \\
OLCI & 2016 & $300-1200$ & $21(400-1020 \mathrm{~nm})$ & $2-3$ \\
GOCI & 2011 & 500 & $8(412-865 \mathrm{~nm})$ & Hourly \\
MSI & 2015 & $10-60$ & $13(443-2190 \mathrm{~nm})$ & 5 \\
Landsat & 1972 & $30-60$ & $4-8(443-2151 \mathrm{~nm})$ & 16 \\
ASTER & 1999 & $15-30$ & $9(560-2390 \mathrm{~nm})$ & 16 \\
\hline
\end{tabular}

ORS sensors on this subject, based mainly on the data availability to a user. Applications of these ORS imagery to oil spill assessment can be found in numerous references, for example, $\mathrm{Hu}$ et al. [11, 12] and Bulgarelli and Djavidnia [13] for MODIS; Sun and Hu [14] for VIIRS; Kolokoussis and Karathanassi [15] for MSI; Taravat and Frate [16], Sun and $\mathrm{Hu}$ [17], and $\mathrm{Lu}$ et al. [18] for Landsat sensors; and Lammoglia and de Souza Filho [19] for ASTER.

Although earlier ORS studies relied primarily on spatial contrasts to detect oil features (e.g., $[20,21]$ ), recent studies started to use more spectral bands to obtain more information from the detected features in order to discard look-alikes, classify oil types, and/or quantify oil concentration or volume. These are based on either visual interpretation of multiband composite images $[5,17,22]$ or analyses of the feature's spectral shapes [18, 23]. Indeed, both theoretical work, based on Monte-Carlo simulations [24-27], and laboratory experimental work under controlled conditions [23, 28-32] suggest a direct connection between multiband or hyperspectral reflectance and oil presence, oil type, and/or oil quantity.

However, these advances have been largely overlooked in some of the recent literature, where disputes on the capacity of ORS in oil spill assessment may create confusion in the research community. For example, in a serious of reviews, Fingas and Brown [2-4] and Fingas [33] still questioned the value of ORS in oil spill assessment, especially on its ability to estimate oil thickness beyond a few micrometers (corresponding to rainbow colors in the field). This is despite being refuted by Svejkovsky et al. [34]. Clearly, the potential and limitations of ORS in oil spill assessments need to be clarified.

Here, based on the most recent literature, this paper attempts to clarify the following concepts: (1) what are the oil's optical properties and how do they impact the spectral reflectance (i.e., color shades) in the vis-NIRSWIR domain? (2) In turn, what is possible and what are the challenges when applying the above knowledge in real-world ORS applications? To address these questions, rather than presenting a comprehensive literature review, we summarize the principles in these two aspects with examples. Interested readers may read the cited literature for more details. Likewise, although passive remote sensing using ultraviolet sun light and active remote sensing using laser-induced fluorescence have also been shown useful, because most satellite sensors are not equipped with such a capacity, they are not discussed here.

\section{Optical Properties of Oil and Oil- Water Mixture}

There are various types of oil in marine oil spills, ranging from crude, lubricating oil, diesel, gasoline, kerosene, and condensate. Even for crude oil, there are still different types, for example, Brent crude oil, West Texas Intermediate, Tapis crude oil, and Middle East crude oil, which have different sulfur content and API gravity (index of the density of a crude oil or refined product). In the marine environments, spills of these various types of oil can come from oil platforms, ship discharge, oil pipeline leaks, unexpected disasters, and land based runoffs [35]. Although reports of the optical properties (absorption, scattering, reflectance) of most of these types have been scarce in the literature, there are some exceptions, from which we may generalize. We believe that although the optical properties of these different oil types may vary, they should follow the same general principles as described below.

2.1. Absorption and Scattering. The complex reflection index, $m=n+i k$, of two types of crude oil, Romashkino and Petrobaltic, has been measured in the laboratory by Otremba [36] (Figure 1 ). Here, the real part ( $n$, commonly called refraction index) defines the surface Fresnel reflectance and together with the size distribution of oil droplets determines the scattering coefficients, which can be modeled using Mie theory (see Chap 3 of [37]). The imaginary part ( $k$ ) determines the absorption coefficient through $a\left(\mathrm{~m}^{-1}\right)=4 \pi k / \lambda$ where $\lambda$ is the wavelength in $\mathrm{m}$ (the visible range of $400-700 \mathrm{~nm}$ corresponds to $4-7 \times 10^{-7} \mathrm{~m}$ ). Otremba [36] proposed that other types of crude oil may have their $n$ and $k$ values bounded by these two types.

These results suggest that for the visible range of $400-$ $700 \mathrm{~nm}$, (1) crude oil has a real refraction index of 1.471.51 , higher than seawater $(\sim 1.34)$, and (2) crude oil has extremely high $a$, which decreases exponentially with increasing wavelengths. At $400 \mathrm{~nm}, a_{\mathrm{oil}}$ ranges between $22,000 \mathrm{~m}^{-1}$ for Petrobaltic and $408,000 \mathrm{~m}^{-1}$ for Romashkino. As a comparison, most seawaters have $a_{\mathrm{sw}}<0.1 \mathrm{~m}^{-1}$ at $400 \mathrm{~nm}$. At $700 \mathrm{~nm}, a_{\mathrm{oil}}$ ranges between $540 \mathrm{~m}^{-1}$ for Petrobaltic and $62,800 \mathrm{~m}^{-1}$ for Romashkino, compared to $a_{\mathrm{sw}}$ of $0.65 \mathrm{~m}^{-1}$.

The absorption measurements have been repeated recently by Clark et al. [23] and Lu et al. [30] using two other types of crude oil, Deepwater Horizon crude oil and Yiyang oil, respectively. Although their magnitudes differ from those reported in Otremba [36], they follow the same patterns: extremely high and exponentially decreasing $a_{\text {oil }}$.

When oil is spilled in seawater, it is often weathered to form emulsions through physical and chemical processes or under human influences (i.e., application of dispersant) [38, 39]. Recently, laboratory experiments further separated them to water-in-oil (WO) emulsions and oil-in-water (OW) emulsions [30]. In the experiments, the only stable state of these oil-water mixtures is $0 \%-1.3 \%$ oil concentration for OW emulsions and $45 \%-100 \%$ oil concentration for WO 


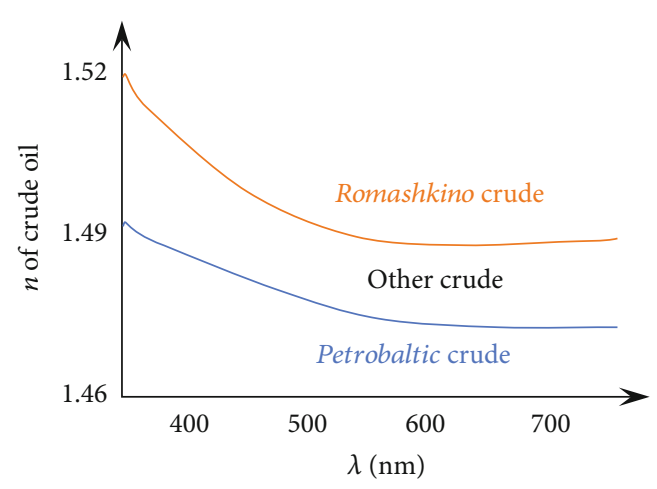

(a)

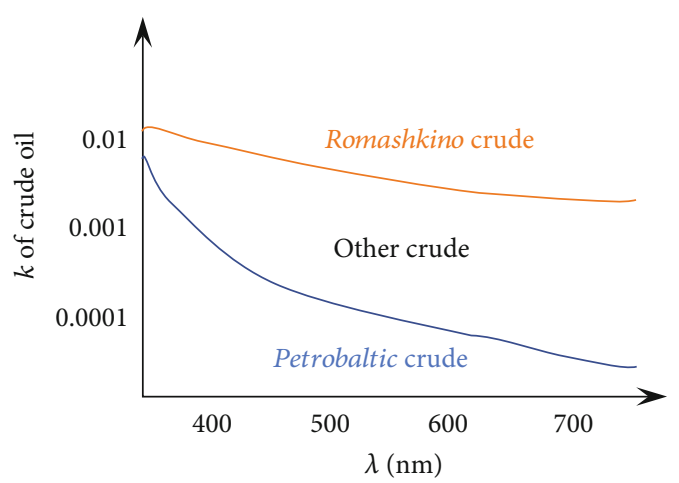

(b)

Figure 1: Real and imaginary parts the complex refraction index crude oil [36].

emulsions. The results from $\mathrm{Lu}$ et al. [30] show that regardless of the oil concentration or oil emulsion type, as long as oil is mixed with water, their absorption coefficients are much higher than pure water, with an exponentially decreasing slope in the visible and NIR wavelengths (Figure 2). The experiments of Clark et al. [23] also showed similar results for the DWH oil emulsions.

From these experiments, the optical properties of crude oils can be generalized as follows: (1) higher refraction index than seawater ( 1.5 versus $\sim 1.34)$, (2) much higher absorption coefficient than seawater in the visible wavelengths regardless of the oil emulsion state (nonemulsified, OW, or WO emulsions), and (3) there has been a lack of scattering measurements in the literature because scattering depends on both refraction index and oil droplet size distributions as well as on oil concentration in the oil-water mixture, yet from the reflectance measurements below, one can infer that oil-water mixture has much higher scattering than seawater in all vis-NIR-SWIR wavelengths.

2.2. Reflectance. Reflectance of various types of crude oil has been measured from controlled experiments in containers of finite size [23, 28-32]. In these experiments, the crude oil in either its original form or after mixing with water to create emulsions was put on top of water, from which spectral reflectance was measured using a portable spectrometer and an artificial light source or sunlight (for outdoor measurements). Although experimental results vary due to different types of oil and different experimental settings, in general, they agree with each other in the following way (Figure 3):

(1) For both oil types (nonemulsified crude oil and oil emulsions), there is no narrow-band reflectance feature in the visible wavelengths, i.e., there is no local reflectance maximum or minimum. This is because of lack of narrow-band features in the oil's complex refraction index. In contrast, there are narrow-band features in the NIR-SWIR spectral range around $1.2,1.4,1.7$, and $2.3 \mu \mathrm{m}$ due to molecular combinations of $\mathrm{C}-\mathrm{H}, \mathrm{CH} 2, \mathrm{CH} 3$, or $\mathrm{O}-\mathrm{H}$ [29]

(2) For nonemulsified crude oil, reflectance decreases with increasing oil thickness, with more negative oil-water contrast in the shorter wavelengths (Figure 3(a), [31]). In the NIR-SWIR wavelengths, reflectance shows virtually no change with increasing oil thickness

(3) For oil emulsions, reflectance characteristics are the opposite of the nonemulsified oil: most changes occur in the NIR-SWIR wavelengths (Figure 3(b), $[23,30])$, including the enhanced reflectance in these wavelengths as well as the local reflectance minima due to the various $\mathrm{C}-\mathrm{H}$ and $\mathrm{O}-\mathrm{H}$ molecular bonds

(4) Between the two types of oil emulsions (OW and $\mathrm{WO})$, there are two distinguishable characteristics. One, while the enhanced reflectance mostly occurs in the NIR wavelengths $(0.7-1.1 \mu \mathrm{m})$ for the OW emulsions, for the WO emulsions such enhancements mostly occurs in the SWIR wavelengths $(1.1-2.2 \mu \mathrm{m})$ (Figure 3(b)). Such a contrast forms the basis to differentiate $\mathrm{OW}$ from $\mathrm{WO}$ emulsions from ORS imagery. Two, while reflectance in the NIR and SWIR increases with increasing oil concentration for OW emulsions (Figure 4(a)), it decreases with increasing oil concentration for WO emulsions (Figure 4(b)). The latter creates an opposite effect from the mixed pixel effect in ORS imagery, making interpretation of oil concentration difficult (see below)

(5) Reflectance of WO emulsions in the NIR and SWIR is a monotonic function of oil thickness when oil concentration is stable in the surface oil layer (Figure 6(b) of [23]). The same phenomenon has been observed independently by Lu et al. [30] (Figure 5(a)). In turn, the later can be derived from the former as long as oil concentration is fixed (Figure 5(b))

The reflectance measurements in the above examples were conducted over different types of crude oil and oilwater mixtures. While other types of oil (diesel, gasoline, condensate, etc.) are still to be measured in a similar fashion, preliminary results of Yang et al. [32] suggest that they appear to follow the general principles presented here. 


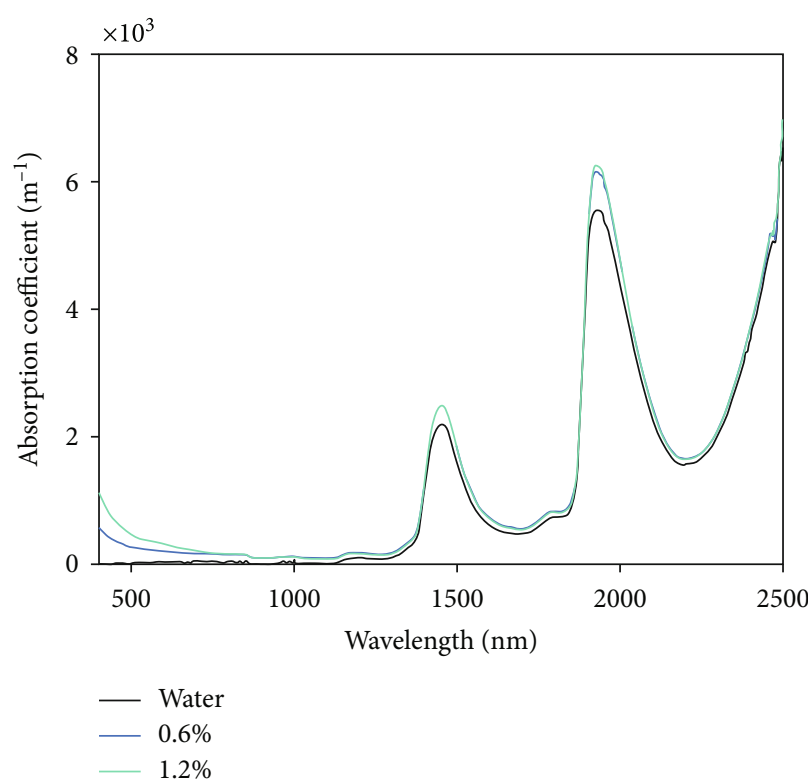

(a)

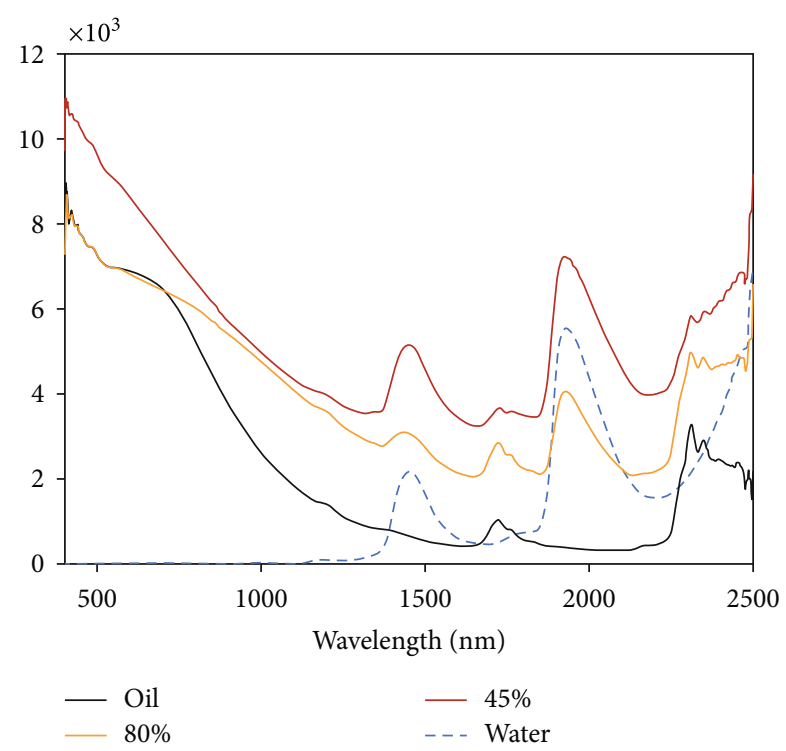

(b)

Figure 2: Absorption coefficients of water, Yiyang crude oil, and their mixture at various concentrations determined from laboratory experiments [30]. The percentage numbers represent oil concentrations in the OW emulsions (a) and WO emulsions (b). These results agree well in principle with those obtained from another type of crude oil from the Gulf of Mexico [23].

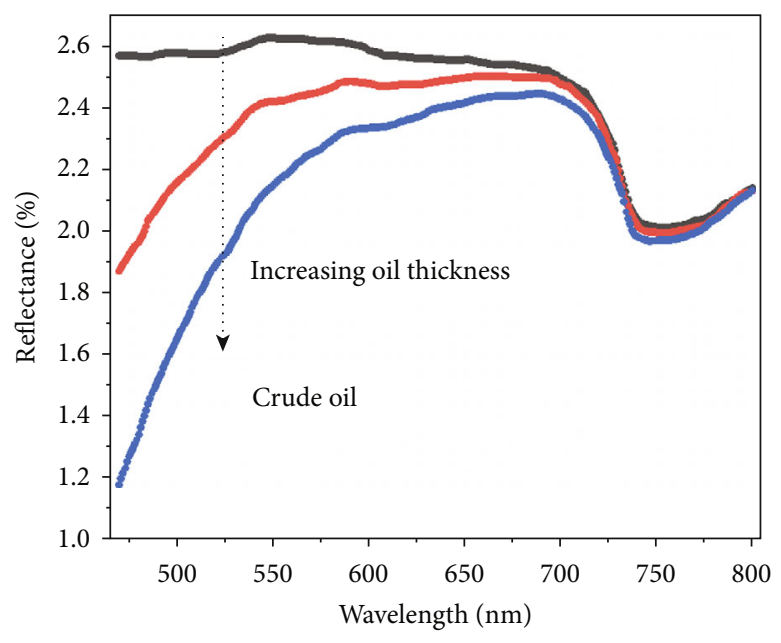

(a)

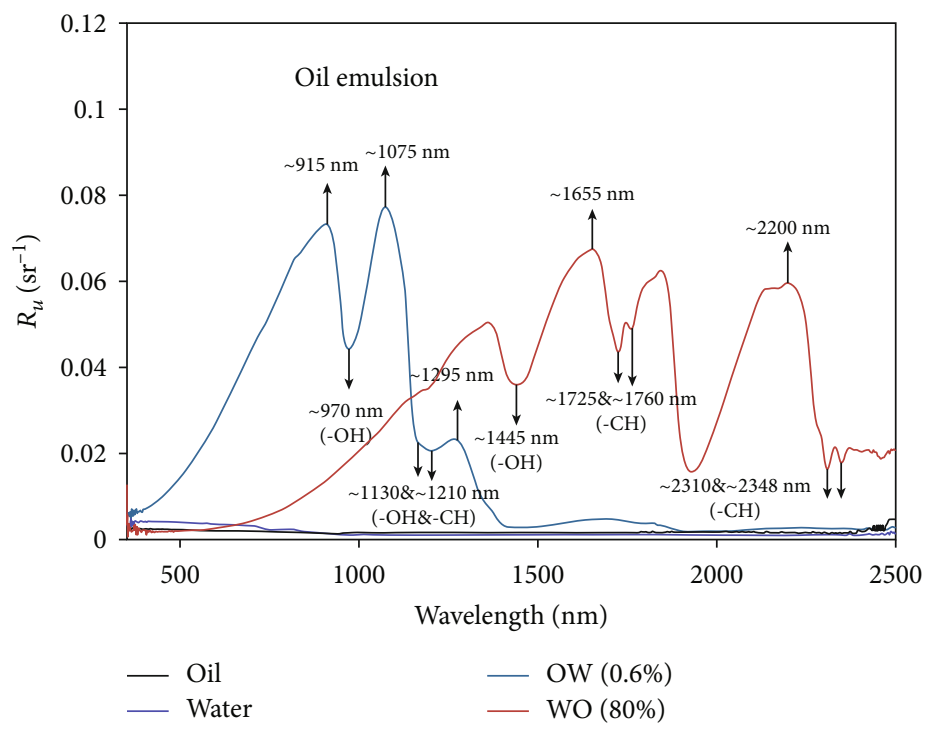

(b)

Figure 3: Reflectance spectra of crude oil (a) and oil emulsions (b) determined from laboratory experiments by Wettle et al. [31] and Lu et al. [30], respectively.

\section{Interpretation of ORS Images}

The inherent optical properties (IOPs) (i.e., complex refraction index in Section 2.1) of crude oil and apparent optical properties (AOPs) (i.e., spectral reflectance in Section 2.2) of various oil types form the basis to interpret ORS images. However, unlike controlled experiments in the laboratory, because ORS images are collected under various atmospheric and oceanic conditions as well as under different observing geometry (collectively, they are called observing conditions), additional factors need to be considered. These include (1) the strength of sun glint, which is a function of primarily wind and observing geometry; (2) the scale of observations and mixed pixels; and (3) water types (clear or turbid). Such factors often make interpretation of ORS images difficult, even though the optical principles are well understood 


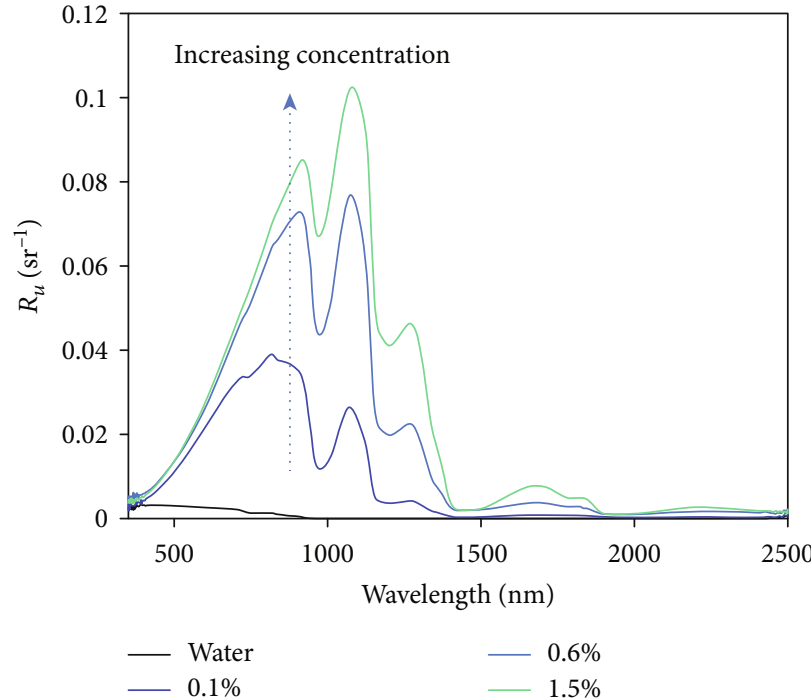

(a)

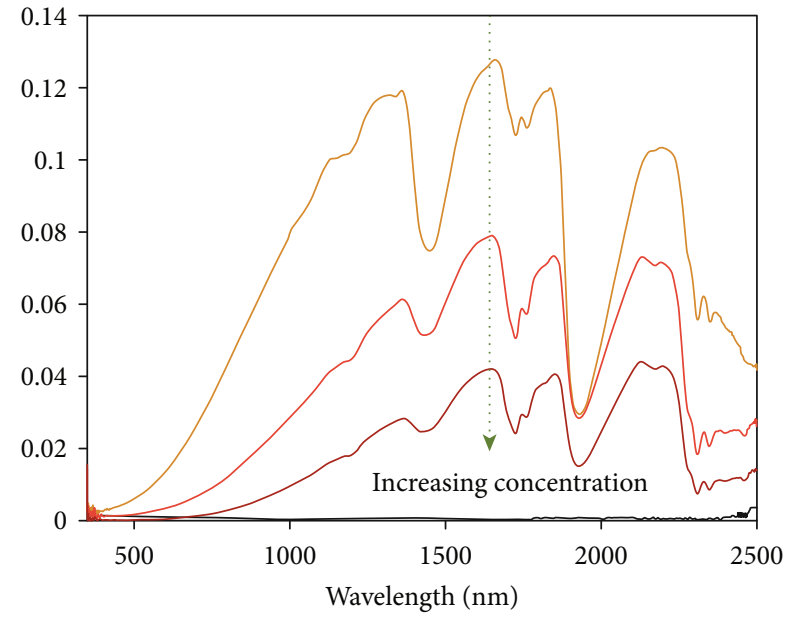

$\begin{array}{ll}\text { Oil } & -70 \% \\ - & -75 \%\end{array}$

(b)

FIGURE 4: Reflectance changes in response to changes in oil concentrations for (a) OW emulsions and (b) WO emulsions [30]. Note the opposite directions as indicated by the dashed arrows.
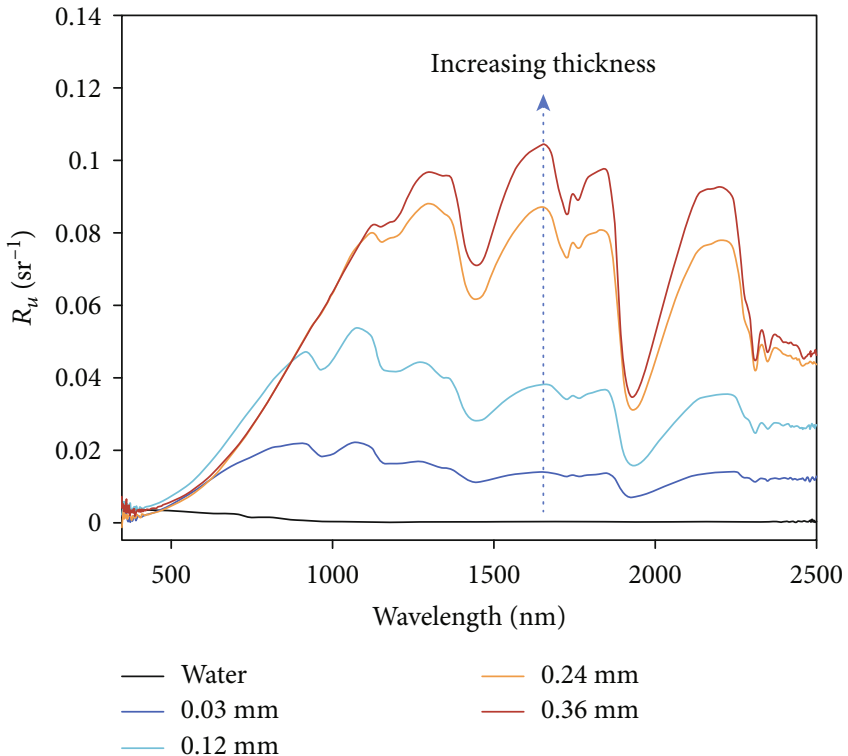

$0.24 \mathrm{~mm}$
$-0.36 \mathrm{~mm}$

(a)

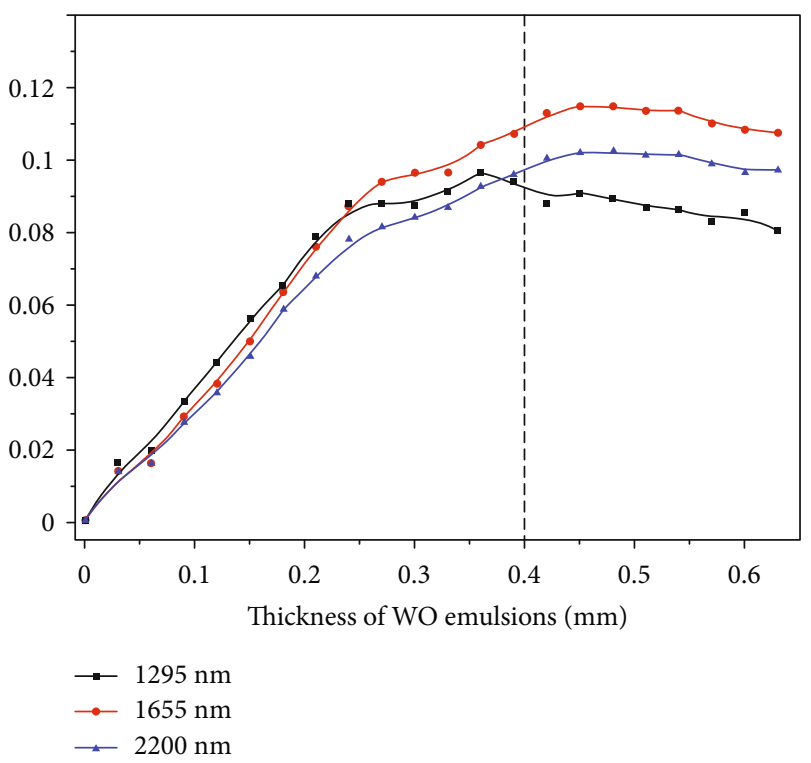

(b)

FIGURE 5: (a) Reflectance of WO emulsions at a fixed oil concentration of 80\%. Note the monotonic increases in the NIR-SWIR wavelengths with increasing thickness. (b) Reflectance in several NIR-SWIR bands as a function of oil emulsion thickness when oil concentration is fixed at $80 \%$. Figure adapted from Lu et al. [30].

(Section 2). Below, we elaborate on how these factors affect the ORS image interpretation through addressing several common questions.

\subsection{Spatial and Spectral Contrasts: Brighter or Darker?} Through a serious a simulations using oil and water IOPs and various observing conditions, Otremba and coworkers $[25,27,40]$ showed that oil-water contrast depends on the oil-on-water condition (pure surface oil layer or oil-water mixture), observing geometry, wind, and wavelength. In other words, there is no simple answer to the simple question of whether oil-on-water is brighter or darker than nearby oilfree water. This is understandable because, depending on the wavelength, sea state (i.e., surface roughness), and observing geometry, the various factors in Section 2 may work together or against each other. For example, oil has a higher refraction index $(\sim 1.5)$ than water $(\sim 1.34)$, leading to higher surface Fresnel reflectance. Therefore, surface oil sheens should 
Table 2: The Bonn Agreement [42] on oil appearance and thickness classes. Note that the color appearance refers to the visible wavelengths where a human eye can capture in the field or from low-altitude aircrafts.

\begin{tabular}{lc}
\hline \multicolumn{2}{c}{ Bonn Agreement } \\
Description/appearance & Thickness $(\mu \mathrm{m})$ \\
\hline Sheen & $0.04-0.3$ \\
Rainbow & $0.3-5.0$ \\
Metallic & $5.0-50$ \\
Discontinuous true color & $50-200$ \\
Continuous true color & $>200$ \\
\hline
\end{tabular}

appear brighter than surrounding waters, and this effect will not be reversed by thin-film optics when oil and water are treated as a two-layer system [36]. When surface oil becomes thicker, oil may appear colorful (also called rainbow sheen, due to light interference) or approach the real true color of pure oil, which is usually darker than the surrounding water due to oil's high absorption coefficient. These form the basis of the Bonn Agreement (Table 2), where five thickness codes are used to interpret the various spatial and spectral contrast of oil on water. The Bonn Agreement has been used by many governmental agencies for visual and airborne oil spill assessment, for example, by the Australian Marine Safety Authority [41] where digital photos are used to illustrate the 5 thickness codes and their appearance.

However, for satellite ORS imagery, the Bonn Agreement is simply not applicable (e.g., no one has been able to observe rainbow color from spilled oil in ORS images) because of

(1) Variable Seawater Reflectance. Due to the variable concentrations of phytoplankton, colored dissolved organic matter, resuspended nonliving particles, and bottom reflectance if the water is optically shallow, reflectance of oil-free water can change by $>1$ order of magnitude, and the reflectance shape (defined by blue/green or red-green band ratios) can also change by $>2$ orders of magnitude [43]. Such a large variability can change the oil-water contrast if the same oil is spilled in different waters. This effect also explains why it is difficult to apply principles established from tank experiment to ORS images-the shallow tank, when not painted black (e.g., the Omesett tank used in [44], or the plastic tank used in [32]), makes the oil-free water very bright, but most seawaters are much darker.

(2) Mixed Pixel Effect. Oil on water is very patchy [45], resulting in mixed pixels. The spatial and spectral contrasts of the oil-containing pixels are the arithmetic means of contrasts from individual oil patches and oil-free water within a pixel, making interpretation more difficult. This is likely one major reason why the reflectance spectral shapes of oilcontaining pixels often appear different from any laboratory-measured spectral shape. Although it might be possible to spectrally unmix the pixel by assuming several end-member oil spectra, currently there is no study to show whether or how such unmixing method works. The mixed pixel effect is also opposite to the reflectance response to oil concentration of WO emulsions (Figure 4(b)), making interpretation even more difficult.

(3) Variable Observing Conditions. This is perhaps the most intriguing factor, which can make the same oil-containing pixel appear completely different in both spatial and spectral contrasts. Such an effect is demonstrated by $\mathrm{Hu}$ et al. ([12], see their Figure 2) and Sun and $\mathrm{Hu}$ ([17], see their Figure 6), where Figure 6 shows a few examples from MISR observations of the DWH oil spill. In these examples, all observing conditions remain the same except the satellite viewing angle. Even though, the same oil slick may turn from positive to negative contrasts or vice versa, where their reflectance spectral shapes also change [17]. While the BRDF plays a role, this contrast reversal is mainly due to changes in sun glint strength $\left(L_{\mathrm{GN}}, \mathrm{sr}^{-1}\right)$, which can be estimated from wind and solar/viewing geometry [46] using the Cox and Munk [47] model. The presence of weak to moderate sun glint can facilitate detection of oil spills $[11,48]$, yet stronger sun glint may not only reverse the spatial contrast but also change the spectral shape $[14,17,49,50]$. From statistical analysis of MODIS, VIIRS, and Landsat images, the following can be generalized on sun glint (Figure 7).

(i) When $L^{\mathrm{GN}}$ is $<10^{-6} \mathrm{sr}^{-1}$, oil-water contrast due to surface roughness changes is negligible in MODIS or VIIRS imagery, suggesting that thin oil films cannot be detected

(ii) When $L_{\mathrm{GN}}$ is $>10^{-6} \mathrm{sr}^{-1}$ but $<10^{-3} \mathrm{sr}^{-1}$, sun glint interference to the reflectance spectral shape of oilcontaining pixels can be neglected, making it possible to use false-color RGB images to show the various color shapes of oil slicks. Figure 8 presents two examples using AVIRIS and Landsat- 8 observations. In these examples, the wavelengths in the SWIR, NIR, and red are used as the red, green, and blue channels to compose the RGB images, where different color shades (reddish or greenish) indicate different emulsion types. These are confirmed by the spectral shapes extracted from representative pixels

(iii) When $L_{\mathrm{GN}}$ is $>10^{-3} \mathrm{sr}^{-1}$ but $<10^{-2} \mathrm{sr}^{-1}$, sun glint interference to the reflectance spectral shape of oilcontaining pixels becomes more apparent, making interpretation of oil types difficult although still possible. At $L_{\mathrm{GN}}>10^{-2} \mathrm{sr}^{-1}$, the sun glint interference becomes dominant in the spectral shape, making all laboratory-established rules inapplicable 

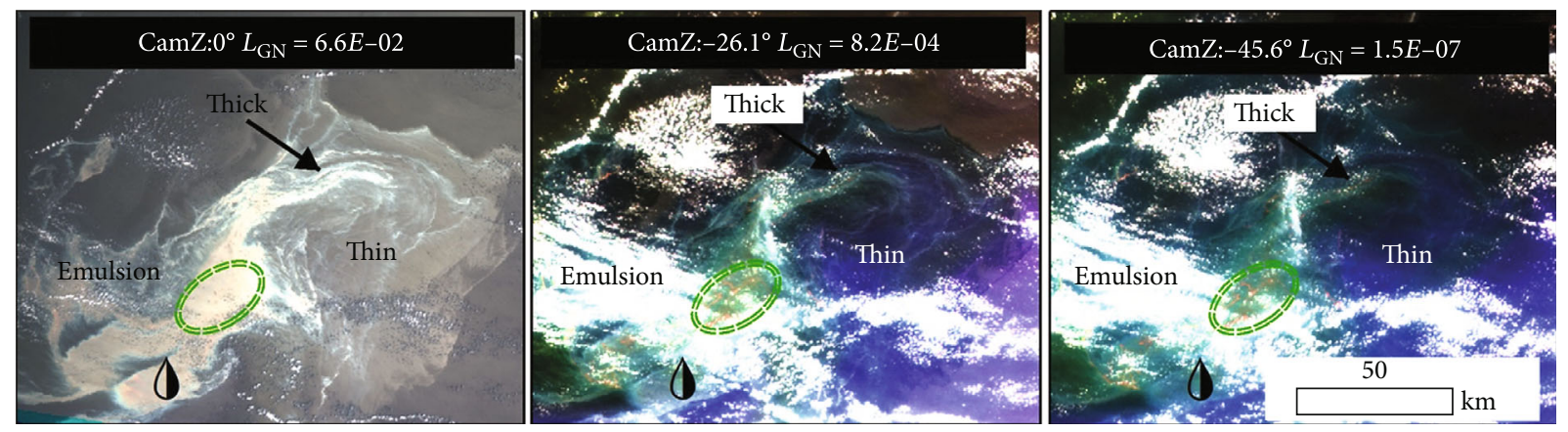

FIGURE 6: MISR images collected over the DWH oil spill site on 17 May 2010, 16:43 GMT. The RGB images are composed using $867 \mathrm{~nm}$ (R), $558 \mathrm{~nm}(\mathrm{G})$, and $446 \mathrm{~nm}(\mathrm{~B})$. The viewing angles and sun glint strengths are annotated. The DWH oil rig location is annotated with a blackwhite symbol. Figure adapted from Sun and $\mathrm{Hu}[17]$.

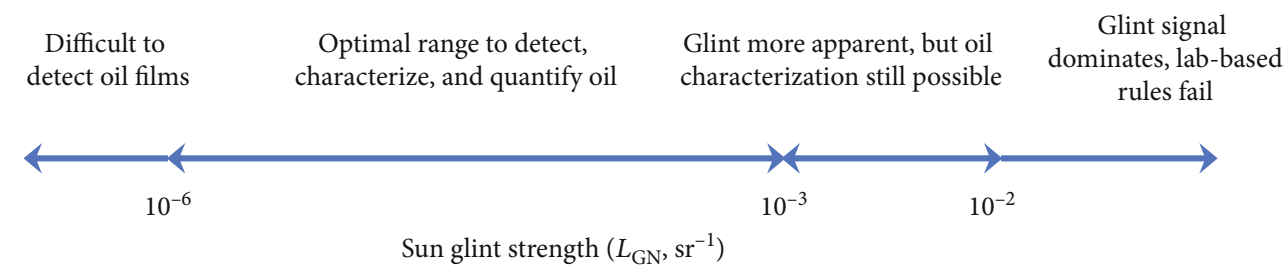

FIGURE 7: Schematic graph showing how sun glint may impact the detection and characterization of oil spills [14, 17]. Statistics were generated using MODIS and VIIRS data. How they may change with finer-resolution data requires more studies.

From these observations, to assess oil spills beyond simple presence/absence detection, the optimal $L_{\mathrm{GN}}$ range is $10^{-6}-10^{-3} \mathrm{sr}^{-1}[14,17]$.

3.2. Oil Classification: What Is Possible? From the examples above, it is clear that when $L_{\mathrm{GN}}$ is $<10^{-3} \mathrm{sr}^{-1}$, the three types of oil (nonemulsified crude, either sheen or thicker, OW, and WO emulsions) have distinguishable spectral shapes (Figure 8), based on which stepwise classification can be performed $[17,18]$. Figure 9 shows two examples corresponding to the AVIRIS and Landsat-8 RGB images in Figure 8. In such classifications, the pixels of greenish colors in Figure 8 have higher reflectance in the NIR than in the SWIR, therefore are classified to be OW emulsions. Likewise, the pixels of reddish colors in Figure 8 have higher reflectance in the SWIR than in the NIR, therefore are classified to be WO emulsions.

However, before the above classification is applied to an ORS image, the first job is to determine which pixels contain oil. This alone is not trivial because many surface floating organisms or materials may cause similar spatial contrasts as oil slicks, for example, floating macroalgae, microalgae, pumice rafts, or unknown features [51, 52]. In other words, except for the SWIR wavelengths where $\mathrm{C}-\mathrm{H}$ and $\mathrm{O}-\mathrm{H}$ absorption features are unique to hydrocarbons, oil does not have spectral signatures in the visible and NIR wavelengths. When the SWIR signal is small due to mixed-pixel effect, classifying oil-containing pixels from other surface features will rely on feature morphology, knowledge on local environment, or simple classification to rule out other possibilities (e.g., [10]). This is similar to classifying oil-containing pixels using SAR imagery.
3.3. Oil Quantification through ORS: What Is Possible? For oil emulsions, after image pixels are classified to contain either OW or WO emulsions, the principles shown in Figure 4 can be used to estimate oil concentration in each pixel for each class, as shown in Figure 9. However, because of the unknown mixing within each pixel and because how such principles are modulated in the real environment, the oil concentrations are expressed in relative sense.

When hyperspectral data in the SWIR wavelengths are available, it is possible to estimate the absolute oil volume based on the magnitudes of the $\mathrm{C}-\mathrm{H}$ absorption features from preestablished spectral library. Clark et al. [23] developed the USGS Tetracorder shape-matching algorithm to quantify oil volume per AVIRIS pixel. Unfortunately, such hyperspectral data are scarce-even during the DWH oil spill AVRIS flight lines could cover only a small portion of the northeastern Gulf of Mexico.

When only multispectra data are available such as those from MODIS or Landsat, based on the principles in Figure 5(b), quantifying oil thickness after oil type classification is still possible. For fixed oil concentration, reflectance in the SWIR is proportional to oil thickness (or oil volume per pixel). This provides the basis to estimate oil thickness, at least on a relative sense. When AVIRIS results derived from the Clark et al. [23] approach are available, the relative thickness derived from MODIS can be calibrated to absolute thickness through matching AVIRIS and MODIS data [12]. This way, the advantage of AVIRIS is scaled up to MODIS coverage, resulting in estimates of oil thickness in the entire oil footprint. Figure 10 shows such an example.

For nonemulsified oil, because reflectance in the blue decreases with increasing thickness (Figure 3(a)), a simple 


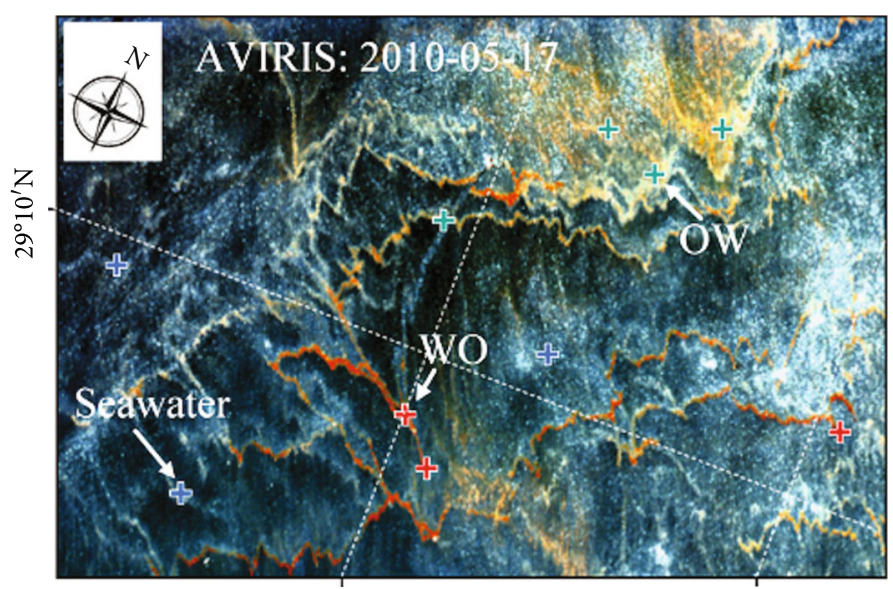

$88^{\circ} 10^{\prime} \mathrm{W}$

$88^{\circ} 08^{\prime} \mathrm{W}$

(a)

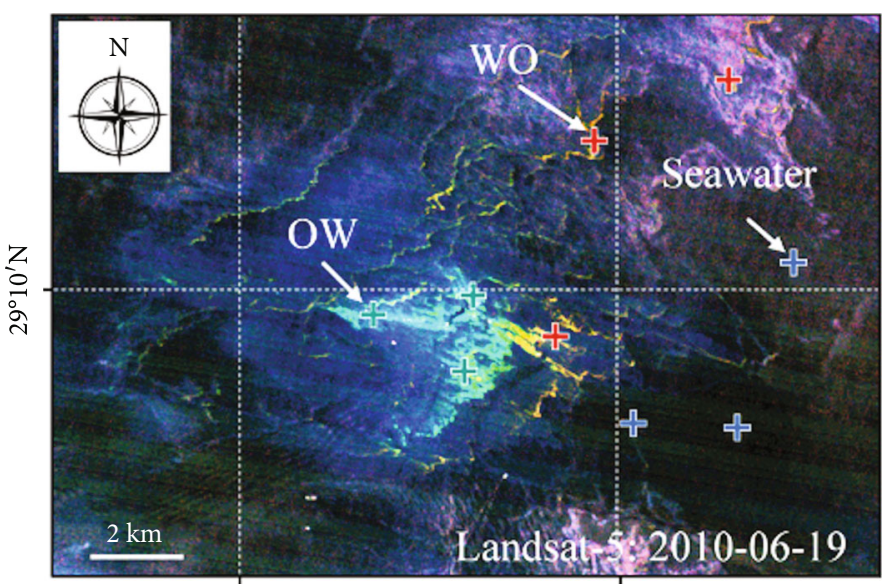

$87^{\circ} 55^{\prime} \mathrm{W}$

$87^{\circ} 50^{\prime} \mathrm{W}$

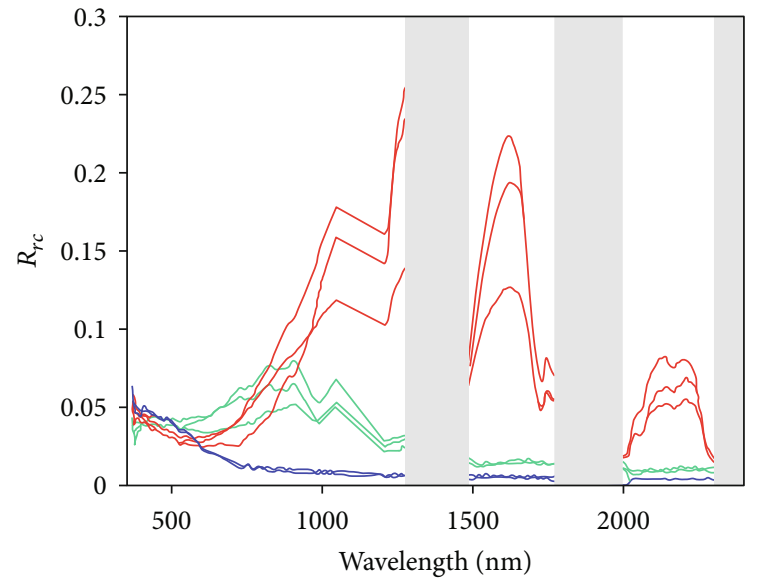

- WO

- OW

_ Seawater

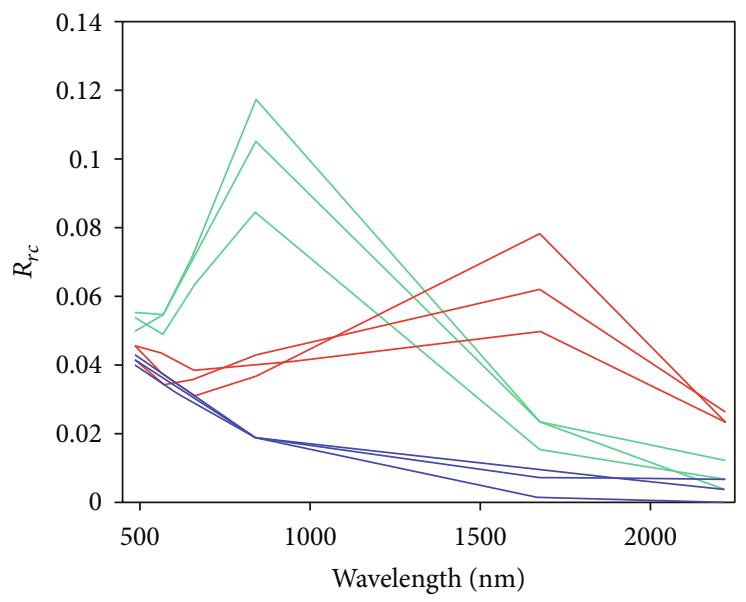

— WO

- OW

_ Seawater

(b)

FIGURE 8: False-RGB showing different oil emulsions from AVIRIS observations (a) and Landsat-8 observations (b), where sample spectra are shown to the right. AVIRIS RGB channels are $1672,831.5$, and $647.8 \mathrm{~nm}$, respectively. Landsat- 8 RGB channels are 1650 , 835 , and $661 \mathrm{~nm}$, respectively. Classification results are presented in Figure 9.

2-layer model can be used to estimate the thickness of the surface oil layer as $[17,31,53,54]$

$$
T=\frac{1}{2 k} \ln \left(\frac{R_{w}-R_{o}}{R-R_{o}}\right)
$$

where $R_{w}$ is the reflectance of oil-free water, $R_{o}$ is the asymptotic reflectance of thick oil, $K$ is the oil diffuse attenuation coefficient that may be approximated to be the absorption coefficient, and $R$ is the reflectance of the oil-containing pixel.

In practice, because different crude oil may have different $R_{o}$ and $K$ and these variables are often unknown, it is difficult to estimate the absolute thickness using Eq. (1). However, it is still possible to estimate the relative thickness once a pixel is determined to contain nonemulsified oil, as shown in Sun and $\mathrm{Hu}$ [17].

In summary, based on the above results, stepwise rules may be established to detect and classify oil-containing pixels as well as to quantify oil concentration or oil volume as follows $[17,18]$ :

(1) Delineate oil-containing pixels based on their spatial contrast, feature morphology, and regional oceanography

(2) For oil-containing pixels whose estimated $L_{\mathrm{GN}}$ is $<10^{-3} \mathrm{sr}^{-1}$, classify them to nonemulsified oil and oil emulsions based on whether their NIR and SWIR reflectance are much higher than nearby 

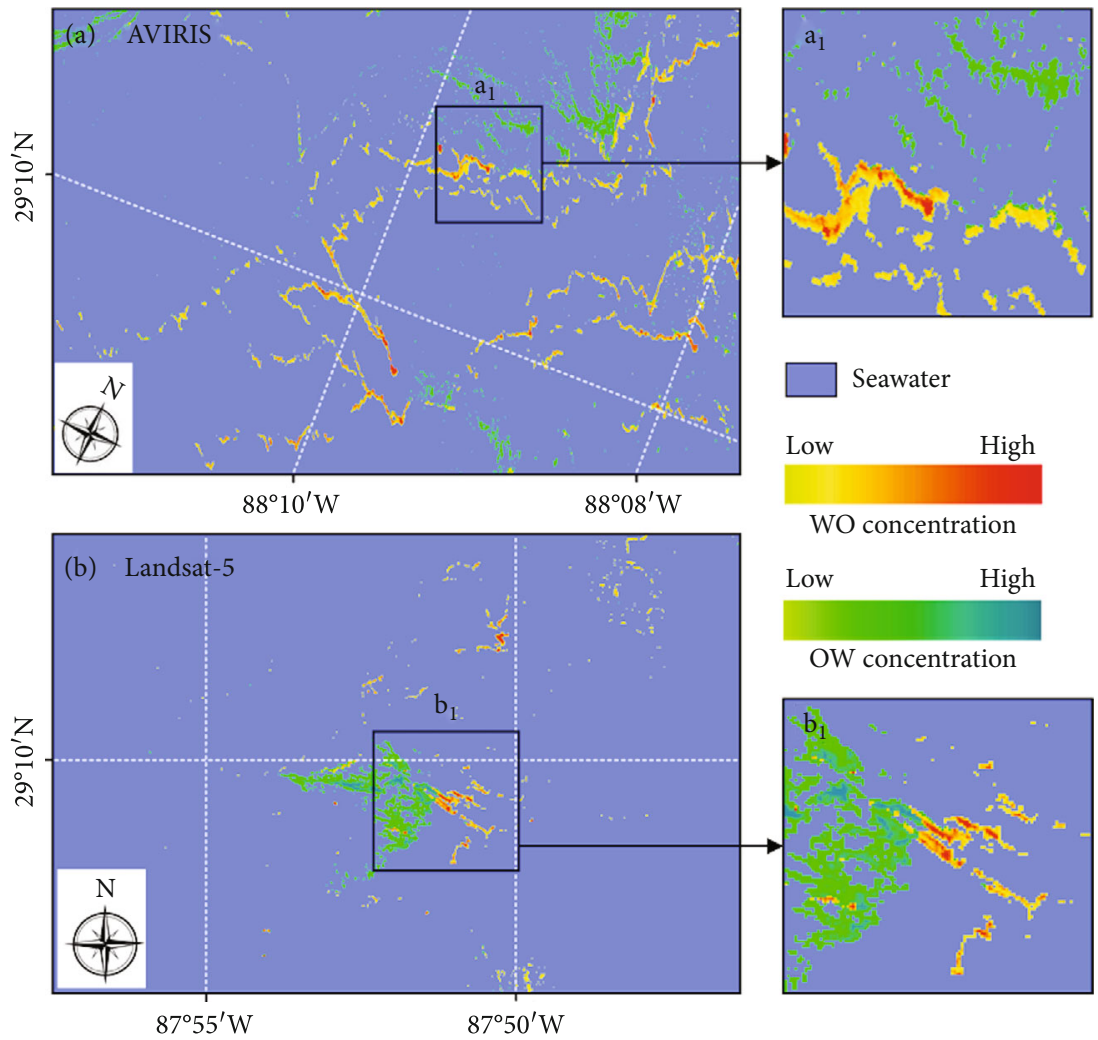

FIGURE 9: Oil classification and quantification results for AVIRIS (a) and Landsat-8 (b) corresponding to Figure 8. Note that because of lack of validation, oil concentration is estimated in relative units.

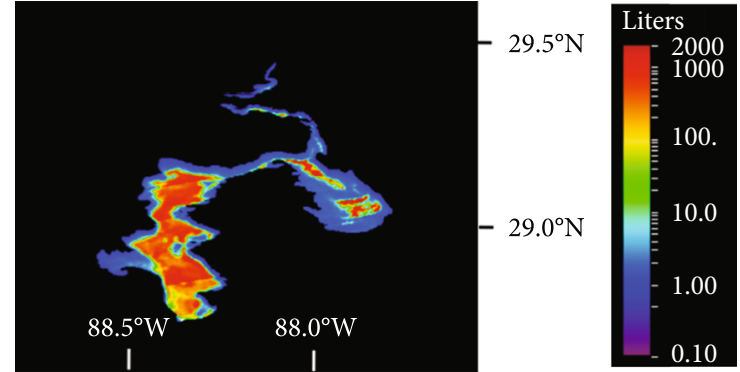

FIGURE 10: Oil volume per MODIS $250 \mathrm{~m}$ pixel estimated using MODIS data in the SWIR wavelengths and calibration data from AVIRIS [12].

water pixels. For the former, Eq. (1) may be used to estimate the relative thickness of the surface oil layer

(3) The oil emulsion pixels are further classified into OW emulsions and WO emulsions based on their relative spectral shapes between NIR and SWIR wavelengths (Figures 8). Relative oil concentrations can then be estimated, respectively, from these two types using laboratory-established rules (Figure 9)

(4) Assuming fixed oil concentration in the WO emulsions, the thickness of the emulsion layer can also be estimated for up to $400 \mathrm{~mm}$ (Figures 5(b) and 10).
When hyperspectral data in the NIR-SWIR wavelengths are available (e.g., from AVIRIS), it is possible to estimate both oil concentration and oil volume in each pixel, from which the thickness of the surface oil layer can be estimated [23]

\section{Challenges}

4.1. Nonoptimal Observing Conditions. As discussed in Section 3.1, ORS images can be collected under nonoptimal conditions, making interpretations difficult even though all governing rules are well understood from laboratory experiments. These mainly include variable seawater reflectance, mixed pixel effect, and variable sun glint strength, and these factors may work together or against each other to make interpretation even more difficult. Figure 11(a) shows such an example from the HICO measurements over the DWH oil spill. Several oil-containing pixels (through visual inspection) are analyzed for their spectral shapes referenced against nearby oil-free pixels. These pixels appear to contain either oil emulsions (pixels 1 and 2) or nonemulsified oil (pixel 3), yet their spectral shapes in Figure 11(b) do not resemble those in Figure 3(b) for oil emulsions or Figure 3(a) for nonemulsified oil. Both pixels 1 and 2 show positive contrasts from nearby water, but the reflectance in the NIR is not much higher than in the visible, contrary to those shown in Figure 3(b). Likewise, although pixel 3 shows negative 


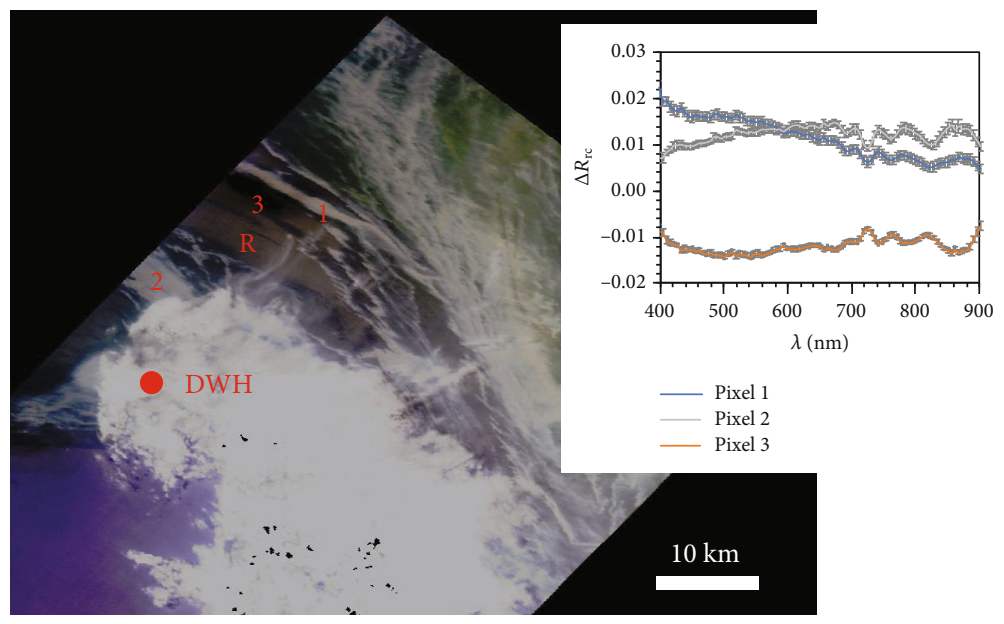

Figure 11: HICO image collected on 12 May 2020 showing oil slicks around the Deepwater Horizon oil rig (red dot, $28.7366^{\circ} \mathrm{N}$, $88.3660^{\circ} \mathrm{W}$ ). The image covers an area of $28.5-29.1^{\circ} \mathrm{N}$ and $88.5-87.7^{\circ} \mathrm{W}$. Three locations are selected to analyze their spectral contrasts against a nearby water location (marked as " $\mathrm{R}$ " for reference), whose spectra are shown to the right. The $y$-axis shows the Rayleigh corrected reflectance $\left(R_{\mathrm{rc}}\right)$ referenced against the water pixel. Each spectrum is a $3 \times 3$ average over the center location, where vertical bars indicate standard deviations.

contrast from nearby water, the contrast is nearly the same in all wavelengths, contrary to those shown in Figure 3(a). It is therefore difficult to classify these pixels based on the rules established above. Clearly, more work is required to understand what caused such spectral shapes.

4.2. Automation. To date, all oil spill applications of ORS imagery require some degrees of manual work or at least human inspection to help delineate oil footprint, from which objective and stepwise classification methods may be applied. This is mostly because of the difficulties in discarding pixels containing clouds, cloud shadows, or other features that make automatic delineation difficult. For example, for the DWH oil spill assessment, none of the existing cloudmasking methods worked because they were not designed to mask clouds in the presence of oil emulsions and strong sun glint [12]. Even the time-consuming cloudmasking through a probability density function (PDF) still resulted in occasional artifacts. Although manual work is acceptable for individual oil spill cases, it makes it difficult or impossible to process long-term time series data in large regions for systematic oil spill assessment. How to minimize such manual effort requires further investigations.

4.3. Validation and Uncertainties. While validating ORSderived oil presence/absence is relatively easy through field observations, validating other derived oil characteristics (emulsion type, concentration, volume, or thickness) is difficult because (1) it is extremely difficult to measure surface oil concentration, volume, or thickness in the wavy sea from a moving boat (see review by [33]), and (2) oil-on-water is very patchy (submeter to meter scale). Even if (1) is possible, the difficulty in (2) will make it nearly impossible to relate the field measurement to a colocated ORS image pixel. Such a problem of mixed pixel effect is not only typical for oil spill remote sensing but also typical for remote sensing of small surface features such as Sargassum or Ulva macroalgae. Indeed, to our best knowledge, no oil spill remote sensing paper has quantitative validations using field measurements due to the above difficulties.

However, this does not mean that uncertainties cannot be quantified using other means. One such method is through the use of high-resolution (e.g., meters) data or fieldcollected digital photos. Although the information from these data is rather qualitative, they can still be used in a statistical fashion to evaluate the classification results from coarse-resolution sensors [12]. Another way is to correlate with field mitigation effort (e.g., burning, booming, and physical collection), as the effort is mostly targeted to thick oil only. In turn, once the classified results are validated this way, they can be used to guide field mitigation activities.

4.4. Recommendation for Future Efforts. Based on the demonstrations above, it is understood that under which observing conditions detecting, classifying, and quantifying oil spills are possible using ORS imagery and, more importantly, how to perform these tasks. It is also understood that under what observing conditions such tasks are difficult or impossible to carry out. With this knowledge, developed methodology, and availability of multisensor data, it is expected that ORS imagery will be more and more used in an operational fashion to assess oil spills in the ocean. One such application is to find the location of "actionable" oil which can be burned or skimmed; in such cases, only relative thickness is relevant. However, there is still a lot of room to further improve the technology in a number of aspects.

First, most laboratory or outdoor experiments have nonrealistic water environments because the containers are either too small or too bright, or the water in the containers does not mimic the typical ocean waters. More experiments using more realistic facilities are required to improve oil quantification. 
Second, because interpretation of oil types becomes difficult once $L_{\mathrm{GN}}$ is $>10^{-2} \mathrm{sr}^{-1}$, and because the current model to estimate $L_{\mathrm{GN}}$ is for oil-free water, more effort is required to model and remove $L_{\mathrm{GN}}$ from oil-containing pixels. For example, measurements from polarimeters, which will be available from the NASA PACE mission (Plankton, Aerosol, Cloud, ocean Ecosystem), may be used to estimate refraction index of the surface layer [55], therefore helping to estimate $L_{\mathrm{GN}}$ from an oiled surface instead of from oil-free water.

Third, because one major obstacle in interpretation comes from the mixed pixel effect, more effort is required to understand how various oil patches, after linear combination within a pixel, may change the pixel's spectral response and, in turn, how to unmix the pixel's spectra to estimate oil type and quantify oil concentration or volume at subpixel scale.

Finally, more effort is required to develop reliable methods to measure or estimate oil thickness in the field in order to provide a direct validation of satellite-based estimates. Even if oil is patchy, a large number of measurements randomly in a large area are still useful for validating pixelwise estimates from ORS images.

\section{Summary and Conclusion}

In ORS imagery, oil-containing pixels can be detected and characterized for two reasons, both due to oil's optical properties: oil has a higher refraction index than water, thus can change surface Fresnel reflectance from the oil-modulated surface roughness, and oil has much higher absorption coefficient than water and also higher scattering coefficient than water when oil is mixed with water to form emulsions. These properties, combined with the various observing conditions in the ocean, form the fundamental basis to detect oil presence/absence and to characterize oil type and estimate oil concentration or thickness despite various interference factors.

While the detection of presence/absence is not unique to ORS images as SAR can do an equally good or even better job, characterizing oil type and quantifying oil concentration or thickness (even in a relative sense) make ORS advantageous over other technique on oil spill assessment. This is especially true when considering that many multiband ORS sensors at various spatial resolutions and revisit frequencies are currently in orbit with data freely available. The question is how to take advantage of such a capacity, how to interpret the imagery data, and how to understand uncertainties and limitations.

Through reviewing the most recent literature and through demonstrations, we hope to clarify the confusion in the community on the potentials and limitations of ORS technique in oil spill assessment. Specifically, ORS offers the capacity beyond field-based visual interpretation of oil spills, and the capacity is also well beyond those summarized in recent reviews [2-4]. In particular, in both theory and practice, the following are possible with ORS imagery as long as there are spectral bands in the visible, NIR, and SWIR wavelengths:
(1) Detect surface oil presence/absence

(2) Classify oil types as nonemulsified, OW emulsions, and WO emulsions from the detected oilcontaining pixels

(3) Quantify oil concentrations in all three types in relative units

(4) Quantify oil volume or thickness per image pixel of up to $400 \mu \mathrm{m}$

If SWIR bands are not available, differentiating OW from WO emulsions becomes difficult, but it is still possible to differentiate nonemulsified oil from oil emulsions. On the other hand, the availability of hyperspectral data in the SWIR wavelengths makes it possible to quantify oil volume at subpixel scale.

All these possibilities are based on the physical principles. However, more work is required to improve such qualitative and quantitative interpretations of ORS imagery, especially regarding validations and uncertainty estimations. With more satellites carrying OSR sensors being launched in the orbit in the coming decade including NASA's PACE mission, we expect to see increased usage of ORS imagery in oil spill assessments.

\section{Conflicts of Interest}

The authors declare that there are no conflicts of interest regarding the publication of this article.

\section{Authors' Contributions}

C. $\mathrm{Hu}$ contributed to the conceptualization, manuscript structure, and manuscript preparation. Y. Lu, S. Sun, and Y. Liu contributed to the manuscript preparation.

\section{Acknowledgments}

This work was supported by the University of South Florida, the U.S. NOAA (NA15OAR4320064), and the National Natural Science Foundation of China (No. 42071387). We thank the NASA JPL for providing AVIRIS data and the U.S. Geological Survey for providing Landsat data..

\section{References}

[1] C. Brekke and A. H. S. Solberg, "Oil spill detection by satellite remote sensing," Remote Sensing of Environment, vol. 95, no. 1, pp. 1-13, 2005.

[2] M. Fingas and C. Brown, "Review of oil spill remote sensing," Marine Pollution Bulletin, vol. 83, no. 1, pp. 9-23, 2014.

[3] M. Fingas and C. Brown, "Response to Svejkovsky et al.," Marine Pollution Bulletin, vol. 93, no. 1-2, pp. 298-300, 2015.

[4] M. Fingas and C. Brown, "A review of oil spill remote sensing," Sensors, vol. 18, no. 2, p. 91, 2018.

[5] I. Leifer, W. J. Lehr, D. Simecek-Beatty et al., "State of the art satellite and airborne marine oil spill remote sensing: application to the BP Deepwater Horizon oil spill," Remote Sensing of Environment, vol. 124, pp. 185-209, 2012. 
[6] O. Garcia-Pineda, I. MacDonald, C. Hu et al., "Detection of floating oil anomalies from the Deepwater Horizon oil spill with synthetic aperture radar," Oceanography, vol. 26, no. 2, pp. 124-137, 2013.

[7] B. Minchew, C. E. Jones, and B. Holt, "Polarimetric analysis of backscatter from the Deepwater Horizon oil spill using L-band synthetic aperture radar," IEEE Transactions on Geoscience and Remote Sensing, vol. 50, no. 10, pp. 3812-3830, 2012.

[8] M. D. King, S. Platnick, W. P. Menzel, S. A. Ackerman, and P. A. Hubanks, "Spatial and temporal distribution of clouds observed by MODIS onboard the Terra and Aqua satellites," IEEE Transactions on Geoscience and Remote Sensing, vol. 51, no. 7, pp. 3826-3852, 2013.

[9] C. H. Hooper, The IXTOC I Oil Spill : The Federal Scientific Response, U.S. Dept. of Commerce, National Oceanic and Atmospheric Administration, Office of Marine Pollution Assessment, Boulder, Colorado, 1981.

[10] S. Sun, C. Hu, and J. W. Tunnell Jr., "Surface oil footprint and trajectory of the Ixtoc-I oil spill determined from Landsat/MSS and CZCS observations," Marine Pollution Bulletin, vol. 101, no. 2, pp. 632-641, 2015.

[11] C. Hu, X. Li, W. G. Pichel, and F. E. Muller-Karger, "Detection of natural oil slicks in the NW Gulf of Mexico using MODIS imagery," Geophysical Research Letters, vol. 36, no. 1, article L01604, 2009.

[12] C. Hu, L. Feng, J. Holmes et al., "Remote sensing estimation of surface oil volume during the 2010 Deepwater Horizon oil blowout in the Gulf of Mexico: scaling up AVIRIS observations with MODIS measurements," Journal of Applied Remote Sensing, vol. 12, no. 2, article 026008, 2018.

[13] B. Bulgarelli and S. Djavidnia, "On MODIS retrieval of oil spill spectral properties in the marine environment," IEEE Geoscience and Remote Sensing Letters, vol. 9, no. 3, pp. 398-402, 2012.

[14] S. Sun and C. Hu, "Sun glint requirement for the remote detection of surface oil films," Geophysical Research Letters, vol. 43, no. 1, pp. 309-316, 2016.

[15] P. Kolokoussis and V. Karathanassi, "Oil spill detection and mapping using sentinel 2 imagery," Journal of Marine Science and Engineering, vol. 6, no. 1, p. 4, 2018.

[16] A. Taravat and F. Del Frate, "Development of band ratioing algorithms and neural networks to detection of oil spills using Landsat ETM+ data," EURASIP Journal on Advances in Signal Processing, vol. 2012, no. 1, Article ID 107, 2012.

[17] S. Sun and C. Hu, "The challenges of interpreting oil-water spatial and spectral contrasts for the estimation of oil thickness: examples from satellite and airborne measurements of the Deepwater Horizon oil spill," IEEE Transactions on Geoscience and Remote Sensing, vol. 57, no. 5, pp. 2643-2658, 2019.

[18] Y. Lu, J. Shi, C. Hu, M. Zhang, S. Sun, and Y. Liu, "Optical interpretation of oil emulsions in the ocean -part II: applications to multi-band coarse-resolution imagery," Remote Sensing of Environment, vol. 242, p. 111778, 2020.

[19] T. Lammoglia and C. R. de Souza Filho, "Mapping and characterization of the API gravity of offshore hydrocarbon seepages using multispectral ASTER data," Remote Sensing of Environment, vol. 123, pp. 381-389, 2012.

[20] C. Hu, F. E. Müller-Karger, C. Taylor et al., "MODIS detects oil spills in Lake Maracaibo, Venezuela," Eos, Transactions American Geophysical Union, vol. 84, no. 33, pp. 313-319, 2003.
[21] I. R. Macdonald, N. L. Guinasso, S. G. Ackleson et al., "Natural oil slicks in the Gulf of Mexico visible from space," Journal of Geophysical Research, vol. 98, no. C9, pp. 16351-16364, 1993.

[22] J. Svejkovsky, M. Hess, J. Muskat, T. J. Nedwed, J. McCall, and O. Garcia, "Characterization of surface oil thickness distribution patterns observed during the Deepwater Horizon (MC-252) oil spill with aerial and satellite remote sensing," Marine Pollution Bulletin, vol. 110, no. 1, pp. 162-176, 2016.

[23] R. N. Clark, G. A. Swayze, I. Leifer et al., "A method for quantitative mapping of thick oil spills using imaging spectroscopy," US Geological Survey Open-File Report, vol. 1167, pp. $1-51,2010$.

[24] Z. Otremba, "Oil-in-water emulsion as a modifier of water reflectance," Optica Applicata, vol. 39, pp. 123-128, 2009.

[25] Z. Otremba and J. Piskozub, "Modelling of the optical contrast of an oil film on a sea surface," Optics Express, vol. 9, no. 8, pp. 411-416, 2001

[26] Z. Otremba and J. Piskozub, "Modeling the remotely sensed optical contrast caused by oil suspended in the sea water column," Optics Express, vol. 11, no. 1, pp. 2-6, 2003.

[27] Z. Otremba, O. Zielinski, and C. Hu, "Optical contrast of oil dispersed in seawater under windy conditions," Journal of the European Optical Society - Rapid publications, vol. 8, p. 13051, 2013.

[28] V. Byfield, Optical remote sensing of oil in the marine environment, Ph.D. Thesis, School of Ocean and Earth Science, University of Southampton, Southampton, UK, 1998.

[29] T. Lammoglia and C. R. de Souza Filho, "Spectroscopic characterization of oils yielded from Brazilian offshore basins: potential applications of remote sensing," Remote Sensing of Environment, vol. 115, no. 10, pp. 2525-2535, 2011.

[30] Y. Lu, J. Shi, Y. Wen et al., "Optical interpretation of oil emulsions in the ocean -part I: laboratory measurements and proofof-concept with AVIRIS observations," Remote Sensing of Environment, vol. 230, p. 111183, 2019.

[31] M. Wettle, P. J. Daniel, G. A. Logan, and M. Thankappan, "Assessing the effect of hydrocarbon oil type and thickness on a remote sensing signal: a sensitivity study based on the optical properties of two different oil types and the HYMAP and Quickbird sensors," Remote Sensing of Environment, vol. 113, no. 9, pp. 2000-2010, 2009.

[32] J. Yang, J. Wan, Y. Ma, J. Zhang, and Y. Hu, "Characterization analysis and identification of common marine oil spill types using hyperspectral remote sensing," International Journal of Remote Sensing, vol. 41, no. 18, pp. 7163-7185, 2020.

[33] M. Fingas, "The challenges of remotely measuring oil Slick thickness," Remote Sensing, vol. 10, no. 2, p. 319, 2018.

[34] J. Svejkovsky, A. Lewis, J. Muskat, J. H. S. Andersen, S. Benz, and O. Garcia-Pineda, "Rebuttal to published article "Review of oil spill remote sensing" by M. Fingas and C. Brown," Marine Pollution Bulletin, vol. 93, no. 1-2, pp. 294-297, 2015.

[35] NRC, Oil in the Sea III: Inputs, Fates, and Effects, National Academies Press, 2003.

[36] Z. Otremba, "The impact on the reflectance in VIS of a type of crude oil film floating on the water surface," Optics Express, vol. 7, no. 3, pp. 129-134, 2000.

[37] C. D. Mobley, Light and Water: Radiative Transfer in Natural Waters, Academic Press, 1994. 
[38] R. Belore, K. Trudel, and J. Morrison, "Weathering, emulsification, and chemical dispersibility of Mississippi Canyon 252 crude oil: field and laboratory studies," International Oil Spill Conference Proceedings, vol. 2011, no. 1, article abs247, 2011.

[39] Z. Zhong and F. You, "Oil spill response planning with consideration of physicochemical evolution of the oil slick: a multiobjective optimization approach," Computers \& Chemical Engineering, vol. 35, no. 8, pp. 1614-1630, 2011.

[40] Z. Otremba, "Influence of oil dispersed in seawater on the bidirectional reflectance distribution function (BRDF).," Optica Applicata, vol. 35, pp. 99-109, 2005.

[41] Australian Marine Safety Authority, "Identification of oil on water: aerial observation and identification guide," 2014, January 2014, https://www.amsa.gov.au/sites/default/files/201401-mp-amsa22-identification-oil-on-water.pdf.

[42] Bonn Agreement, "Bonn Agreement aerial operations handbook," 2012, 2009, http://www.bonnagreement.org.

[43] D. Sun, C. Hu, Z. Qiu, and S. Wang, "Reconstruction of hyperspectral reflectance for optically complex turbid inland lakes: test of a new scheme and implications for inversion algorithms," Optics Express, vol. 23, no. 11, pp. A718-A740, 2015.

[44] O. Garcia-Pineda, G. Staples, C. E. Jones et al., "Classification of oil spill by thicknesses using multiple remote sensors," Remote Sensing of Environment, vol. 236, p. 111421, 2020.

[45] S. Sun, C. Hu, L. Feng et al., "Oil slick morphology derived from AVIRIS measurements of the Deepwater Horizon oil spill: implications for spatial resolution requirements of remote sensors," Marine Pollution Bulletin, vol. 103, no. 1-2, pp. 276-285, 2016.

[46] M. Wang and S. W. Bailey, "Correction of sun glint contamination on the SeaWiFS ocean and atmosphere products," Applied Optics, vol. 40, no. 27, pp. 4790-4798, 2001.

[47] C. Cox and W. Munk, "Measurement of the roughness of the sea surface from photographs of the sun's glitter," Journal of the Optical Society of America, vol. 44, no. 11, pp. 838-850, 1954.

[48] M. Adamo, G. De Carolis, V. De Pasquale, and G. Pasquariello, "Detection and tracking of oil slicks on sun-glittered visible and near infrared satellite imagery," International Journal of Remote Sensing, vol. 30, no. 24, pp. 6403-6427, 2009.

[49] C. R. Jackson and W. Alpers, "The role of the critical angle in brightness reversals on sunglint images of the sea surface," Journal of Geophysical Research, vol. 115, no. C9, article C09019, 2010.

[50] Y. Lu, S. Sun, M. Zhang, B. Murch, and C. Hu, "Refinement of the critical angle calculation for the contrast reversal of oil slicks under sunglint," Journal of Geophysical Research: Oceans, vol. 121, no. 1, pp. 148-161, 2016.

[51] C. Hu, L. Feng, R. F. Hardy, and E. J. Hochberg, "Spectral and spatial requirements of remote measurements of pelagic Sargassum macroalgae," Remote Sensing of Environment, vol. 167, pp. 229-246, 2015.

[52] L. Qi, C. Hu, K. Mikelsons et al., "In search of floating algae and other organisms in global oceans and lakes," Remote Sensing of Environment, vol. 239, p. 111659, 2020.

[53] Y. Lu, Q. Tian, and X. Li, "The remote sensing inversion theory of offshore oil slick thickness based on a two-beam interference model," Science China Earth Sciences, vol. 54, no. 5, pp. 678-685, 2011.
[54] Y. Lu, X. Li, Q. Tian, and W. Han, “An optical remote sensing model for estimating oil slick thickness based on two-beam interference theory," Optics Express, vol. 20, no. 22, pp. 24496-24504, 2012.

[55] M. Ottaviani, B. Cairns, J. Chowdhary et al., "Polarimetric retrievals of surface and cirrus clouds properties in the region affected by the Deepwater Horizon oil spill," Remote Sensing of Environment, vol. 121, pp. 389-403, 2012. 